\title{
Organizational Change: Employees Reaction Towards It
}

\author{
PhD.Cand. Gentisa Furxhi \\ Faculty of Economy, University "Fan S.Noli", Korce, Albania \\ gfurxhi@gmail.com \\ Prof.as.dr.Sonela Stillo \\ Faculty of Economy, University "Fan S.Noli", Korce, Albania \\ sonelastillo@yahoo.com \\ Doc. Marinela Teneqexhi \\ Faculty of Economy, University "Fan S.Noli", Korce, Albania \\ marinelapt@yahoo.com
}

\begin{abstract}
The organizations, in the present days, are facing a dynamic environment which makes that no organization is immune towards change. Technological changes, innovations in communication, movements in the job market, globalization, make the organization face continuous challenges regarding competition, general non-stability of the macro-environment, merging and re-engineering of the work processes. To face these challenges, the organization reassesses the strategies, structure, policies, actions, processes and their culture. So the organizational change (OC) is inevitable in the environment where the organizations operate. Organizational change can be a very small change (additional) or it can be fundamental (transformative). Regardless of the form, function or size that the organizatioal change can make, there is an agreement between the community of the researchers that the pace of the organizational change has never been as high as in our days and it must be considered as a "feature which is present in the organizational life both in the operational level as well as in the strategic level" (By, 2005). Researchers already see the organizational change as a feature, present and continuous of the organizational life, inconsistent with the previous conceptualism that viewed the organizations as relatively stable systems, which developed over time through additional planned changes, which took place in regular and predicted phases (Burnes, 2004; Cummings \&Worley, 2009). The famous expression "organizations don't change, people do", creates the need for change agents to understand that employees have different reactions to change initiative, because they have different personal experiences, motivation levels, socio-demographic characteristics, knowledges, values and different behavior models.
\end{abstract}

Keywords: Organizational change, change agents, readiness of the employees, resistance.

\section{Introduction-Organizational change}

The organizational change is defined as the implementation of the strategies, created to change job conduct of the employee in order to improve the organizational performance (Porras \&Roberston, 1992)and that the change can be affected by internal and exterior factors; it can take different sizes and shapes, and can affect all the organizations of the industry. In the organization most of the problems and challenges are created because of the competition, advanced technology, merging, extensions, maintenance of the product quality, or the increasing of the efficiency of the employees on one hand, and the fast growth, new business ventures, interesting opportunities, innovations, and new management approaches on the other. 
The organizational change is defined as a displacement from one stage to another, or the change deals with the breaking down of the existing structures and creating new ones (Chonko, 2004). Barnett and Carroll (1995) defined the change as a transformation between two points in time, to compare the organization before and after the transformation. The change can be small or large; it can be related with the improvement, variation, change or modification of something (Bennett, 2001). Sources of change are internal as well as external pressures associated with the business expansion or with their need to respond to challenges.

Internal factors of change are associated with the growth of the organizations, while the external factors are associated with such cases as the institutional and market instability (Barnett and Carroll, 2005). Despite the form, function or size that the organizational change can take, there is an agreement between the community of the researchers that the rhythm of the organizational change has never been as high as in the present days and it should be considered as a "feature which is present in the organizational life both in the operational level as well as in the strategic level" (By, 2005).

Researchers already see the organizational change as a feature, present and continuous of the organizational life, inconsistent with the previous conceptualism that viewed the organizations as relatively stable systems, which developed over time through additional planned changes, which took place in regular and predicted phases (Burnes, 2004; Cummings \&Worley, 2009).

One of the models of organizational change that explain the difference between the three stages is the Lewin model. This model is created by the psychologist Kurt Lewin in the years 1940 . He recognized three stages of change, which are widely spread even in the present day.

These stages are:

1. Unfreezing,the equilibrium and the current state of the organization.

2. Change, passing to the desired state through regulation and relocation of the old models of conduct

3. Re-freezing, the new conducts defining them as new stable conducts to create equilibrium and the new state of the organization.

Lewin (1947) suggested that the major part of the employees tend to be around some safe zones and they are hesitant towards change. These employees feel comfortable in a constant environment and they don't feel comfortable when a change happens, even a small one. According to Lewin, the organizational leaders should minimize or eliminate the clamping forces that lead to the opposition of change, through creating leading forces pro change, or through using the combinations and tactics that make the employee accept the actual state of the organization and the techniques that create opportunities that the employees will adapt toward organizational change.

According to Lewin, these are tactics mostly used by the organizational leaders (the agents of change) to motivate the employees to accept the change.

These techniques involve:

1. Creation of trust.

2. Clarifying the reason that the actual state of the organization is no longer suitable through a compelling vision for the future desired state.

3. Promotion of the involvement and active participation in design and implementation of the actions for organizational change.

Lewin's three phase model and the efforts of his colleagues was a trampoline for most of the future organizational models of the management process of change (Burnes, 2004; Burnes\&Oswick 2011; Cummings \& Worley 2009; Weick\& Quinn 1999).

In fact these basic elements and tactics are still present in many recent models of leadership of the organizational change.

Perhaps the most well-known is the model of John Kotter (1995-1996). He proposed an eight phase process, which should be followed by the organizational leaders to successfully implement the organizational change: 
1. The increase of the urgency for change.

2. The creation of a group that deals with change.

3. The creation of the vision.

4. Communication.

5. Authorization.

6. The creation of short-term objectives.

7. Persistence.

8. Making a sustainable change.

Another process by Blanchard and his collaborators (2007), also suggests that the organizational leaders should follow a model of eight phases of change: 1 . The expansion of the opportunities for inclusion and impact; 2 . The explanation for the change; 3 . The prediction of the future; 4 . The experimentation to ensure harmonization; 5 . Allowing and encouraging; 6. Commission and approval; 7. Collocation and extension; 8. The search for opportunities.

\section{Employee's reactions toward organizational change}

Numerous studies showed that there is a high percentage of failure in the initiatives for change (Beer and Nohria, 2000). As an answer to the high degree of failures of change, researchers have tried to discover the factors that can increase the chances to the successful implementation of the organizational change. Miller, Johnson and Grau (1994) argued that, the failure of the successful implementation of the change can be dedicated to many factors, some issues are as important as the behavior of the employees toward change. So, the agents of change must focus at the reactions of the employees toward change, which are positive (willingness toward change) or negative (resistance toward change).

Willingness for change is the most common positive attitude toward change, toward which,many studies have been undertaken in the literature of the organizational change. And actually, by reviewing the literature that Bouckenooghe (2010) wrote is concluded that $90 \%$ of the work about the attitudes toward change is defined as "beliefs, attitudes, and individual objectives, about the acceptances that how necessary are the changes and that how capable is the organization to successfully undertake these changes (Armenakis, Harris \&Mossholder, 1993 pg 681)"1. Armenakis and Harris (2002), have discovered five believes that underline the individual willingness for change. Firstly, Armenakis and Harris argue that a message of change should create a feeling of inconsistency or a belief that the change is necessary. So, an individual must believe that the proposed change is appropriate toward a given situation. In addition, Armenakis and Harris argued that a message of change should create the feeling of efficiency that is refered to the abilities that an individual percepts that he has in order to implement an initiative of change (Oreg, Vakola\&Armenakis, 2011). The fourth belief is the initial support, which evaluates the individual trust that the organization (supervisors, colleagues) will create support in terms of information and resources. This belief impacts the understanding of the efficiency of an individual about his ability to implement change. The last belief is valence, which has to do with the evaluation that an individual makes to the benefits and costs of a change.

Chawla and Kelloway (2004, pg 485)2 define the resistance toward change as "participation in every attitude or behavior that prevents the objectives of the organizational changes". A passive reaction can be an expression of fear of losing something precious, a feeling of losing the control caused by fear of an unknown situation, and the fear of failure in the new situation which will probably cause the resistance to change (Tannenbaum and Hanna, 1985, Bridges, 1986; Jick, 1979; Dirks et al, 1996;. Cheim, 2002).

In the literature, the resistance of the employee can be seen better as made of two components such as reactions of attitude and reactions of behavior to change. In the attitude of resistance to change, the reaction of the employee depends on the psychological rejection of change according to need; while the resistance of behavior maybe has to do with individual behaviors that reflect the absence of will to support change or the absence of the will to stay with the organization during this troubled period (the absence of commitment for change) (Chawla and Kelloway, 2004). According to Dent and Goldberg (1999), people not necessary resist change, but meanwhile they resist the loss of status, payment or commodities that can be associated with it. The reaction that manifests itself as anger or fear constitutes the resistance to change. According to

1 "Creating readiness for organizational change", Sage Journals, Human Relations June 1993, Vol

2 "Predicting openness and commitment to change", Leadership and organizational development Journal 
Bove and Hede (2001), resistance is created in an organization because the process of change involves the passing from a known situation in an unknown situation that makes the individuals unreliable. So the employee can develop different thoughts, beliefs and attitudes about the organizational changes. Many researchers have promoted the importance of the perceptions of the employees about the organizational changes (Kotter, 1995; Armenaki et al, 1999, Holt et ak, 2007; Elias, 2009). They argue that most of the failures of the programs of change happen because of the human factors, which are directly related with the individual and workplace determinants. Through these factors, the employee can develop positive attitudes and behaviors that can show the pleasure of the employee toward the organization (Martin et al, 2006).

\section{Case study}

The main goal of our study was to see employee's reactions to changes organizationshave taken duringthe past 10 years. Another goal , of this study was to see if the factors that have affected employee's readiness or employee's resistance to change in developed countries were the same factors affecting attitudes to change to employees in Albania, as a developing country. We studied factors that influence employee's readiness or resistance to change in a sample of 1000 employees in 50 different business organizations (manufacturing, service organizations, banks) in Albania. Some of the most important findings from our collected datas are showen at the figure 3.1.

As it is shown from the chart, all of organizations have taken changes in products/services they produce/offer. This is a domino effect of technological change, due to $90 \%$ of organizations have made changes in manufacturing, communicating technology, etc. Few changes were undertaken to organizational culture, because it is a change which needs longer time to occur.

Success rate of change initiatives is still low (30\%), compared with change failure(70\%), in Albanian business reality (fig.3.2). This high rate of change failure, has a significant link with negative reaction of employees to organizational change, $62 \%$ of them have not accepted change initiative as appropriate to organization( fig.3.3).

Reasons why employees have reacted in this manner, refusing organizational change, are shown in the figure 3.4.

Our study revealed that there were different factors that impacted employees resistance to change. Employees perceived organizational change as e threat to keep personal control to their work, $79 \%$ of them thought that they will lose personal control due to change initiative. One of the most important reasons why employees have not accepted organizational change was fear of loosing their job, only $17 \%$ of employees believed that their job position was safe after change implementation. This uncertainty is due to the fact that major changes were changes in manufacturing technology. Employees who manifested readiness to accept organizational change, believed that change will create higher levels of autonomy at work ( $50 \%$ of them). Also they perceived that change initiative was appropriate with organization need for change (35\%) and $37 \%$ of employees reported management support as a crucial factor to accept change. They had positive feelings to a regular change process which begins with a clear communication to change initiative and ends with necessary trainings.

\section{Conclusions}

Organizational change is an integral part of business organizations. It is created as a result of a gap identification at organizational performance or as a result of new ideas creation. Change can be triggered by external or internal environmental organization factors. Every change is created to improve organizational performance. The success of change implementation and change management depends heavily on perceptions that employees have toward it. Employees have different reactions to change initiative, because they have different personal experiences, motivation levels, socio-demographic characteristics, knowledges, values and different behaviour models. They are more likely to be resistant to change when they feel uncertainty for their work position, when they loose work autonomy and when they are not involved at change initiative. Also, employees will react negatively, when they see there is no need for organization to change, or when they perceive that change initiative is not appropriate to improve organizational change. On another hand, employees are ready to accept change when they are convinced that change is necessary to achieve a desired future condition; when they see that management support really exist; and when change is clearly communicated to them. So, when organization leaders treat employees as human beings and they stay closed to them during change process. Also, as far as employees perceive that the change will bring personal benefits to them (e.g., career growth, higher wages, etc.) 
they are more likely to accept organizational change. At the end, one of tactics that fosters employees to accept and to engage for a successful change management is employees involvement in change project.

\section{References}

1. Armenakis, A. A., \& Harris, S. G. (2011). Sage Journal Online. Retrieved March 2011, from Creating Readliness for Organizational Change

2. Walumbwa, F. O., Cropanzano, R., \& Goldman, B. M. (2011). How leader-member exchange influences effective work behaviors: Social exchange and internal-external efficacy perspectives. Personnel Psychology, 64(3), 739-770

3. Self, D., \&Schraeder, M . (2009). Enhancing the success of organizational change: Matching readiness strategies with sources of resistance. Leadership \& Organizational Development Journal, 30(2), 167-182.

4. Ford, J., \& Ford, L. (2009). Decoding Resistance to Change. Harvard Business Review , 99-104. French, R., Rayner, C., Rees, G., \& Rumbles, S. (2008). Organizational Behavior. Chichester: John Wiley.

5. Self, D. (2007). Organizational change: Overcoming resistance by creating readiness. Development and Learning in Organizations, 21(5), 11-13

6. Walker H. J., Armenakis A. A., \& Bernerth J. B. (2007). Factors influencing organizational change efforts: An integrative investigation of change content, context, process and individual differences. Journal of Organizational Change Management, 20, 761-773.

7. Woodward, S., \& Hendry, C. (2004). Leading and coping with change. Journal of Change Management, 4(2), 155-183.

8. Bennis, W \&Nanus, B (2004), Leaders: strategies for taking charge, 2nd edn, Harper Business, New York

9. Chawla and Kelloway (2004), "Predicting openness and commitment to change", Leadership and organizational development Journal

10. Vansteenkiste, M., Simons, J., Lens, W., Sheldon, K. M., \& Deci, E. L. (2004). Motivating learning, performance, and persistence: The synergistic role of intrinsic goals and autonomy-support. Journal of Personality and Social Psychology, 87, 246-260.

11. Weber, P., \& Weber, J. (2001). Changes in employee perceptions during organizational change. Leadership \& Organization Development Journal, 22(5/6), 291-300.

12. Strebel, P. (1996). Why do employees resist change? Harvard Business Review, 74(3), 86-92.

\section{Figures}

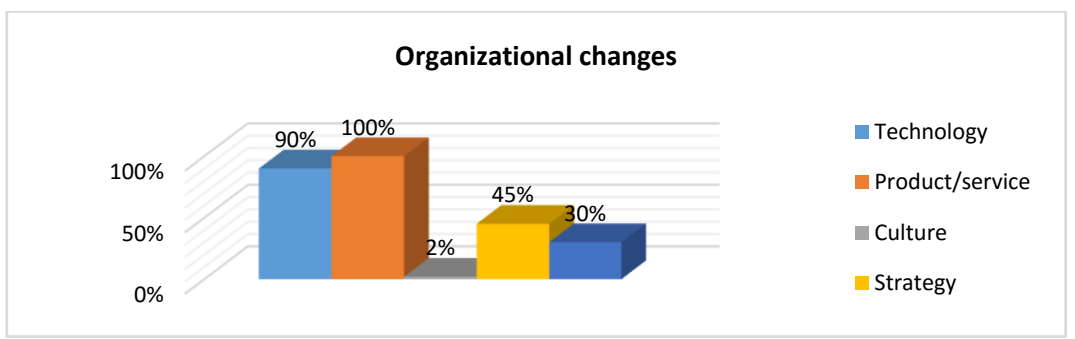

Fig 3.1: Organizational changes 


\section{Change Management}

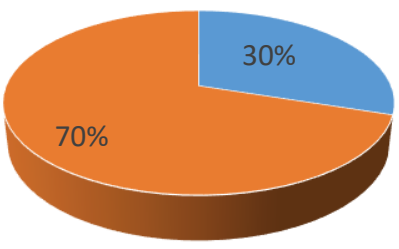

- Successful Unsuccessful -

Fig 3.2: Change management effectiveness

\section{Employees reactions to change}

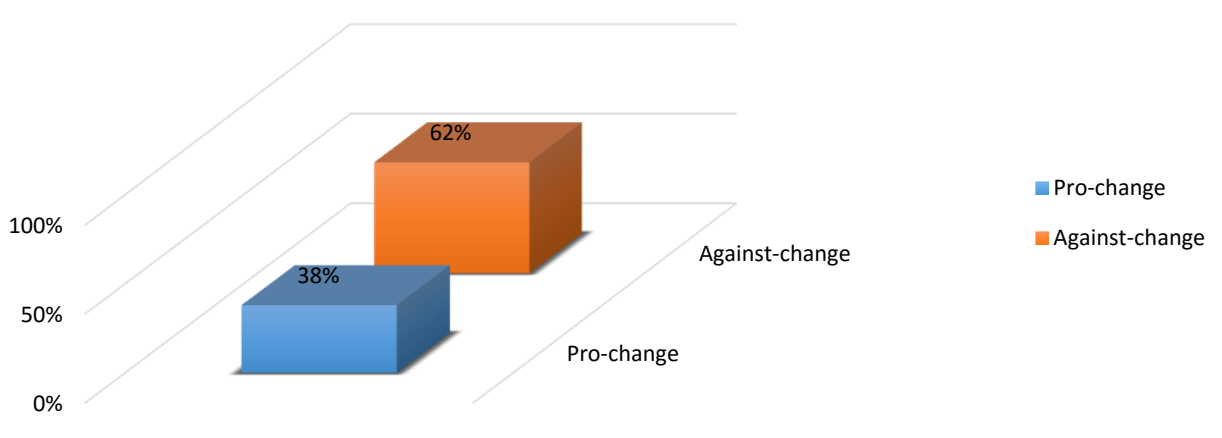

Fig 3.3: Employees reactions to organizational change

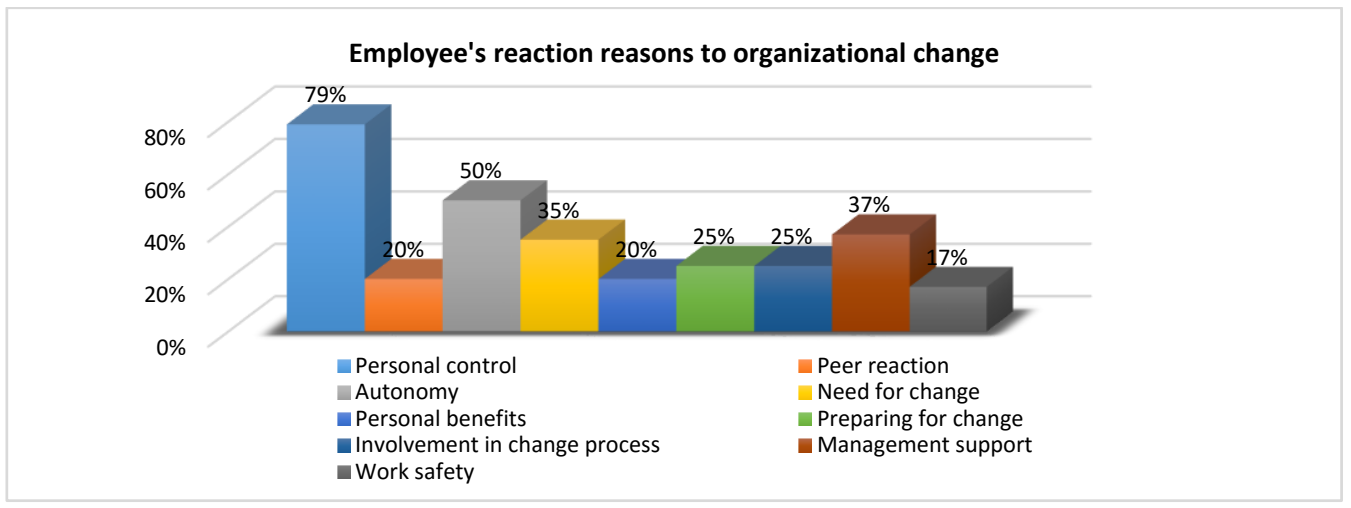

Fig 3.4: Reasons of employee reaction to organizational change 